\title{
Complications, revision fusions, re-admissions and utilization over a one-year period following bone morphogenetic protein use during primary cervical spine fusions
}

\author{
Adam P. Goode, DPT, PhD [Assistant Professor], \\ Department of Community and Family Medicine, Duke University School of Medicine, Durham, \\ NC \\ William J. Richardson, MD [Professor of Orthopedic Surgery], \\ Chief Division of Spine Surgery, Duke University School of Medicine, Durham, NC \\ Robin M. Schectman, MSPH [Applications Analyst], and \\ Cecil G. Sheps Center for Health Services Research, University of North Carolina at Chapel Hill \\ Timothy S. Carey, MD, MPH [Professor of Medicine and Epidemiology] \\ Director of Cecil G. Sheps Center for Health Services Research, University of North Carolina at \\ Chapel Hill
}

\section{Abstract}

Background-Nationwide estimates examining Bone Morphogenetic Protein (BMP) use with cervical spine fusions have been limited to perioperative outcomes.

Purpose-Determined the one-year risk of complications, cervical revision fusions, hospital readmissions and healthcare services utilization.

Study Design/Setting -A retrospective cohort study from 2002 to 2009 utilizing a nationwide claims database.

Patient Sample-There were 61,937 primary cervical spine fusions of which 1,677 received BMP.

Outcome Measures-Complications, revision fusions, 30-day hospital readmission and healthcare utilization.

Methods-Data for these analyses come from the Thompson Reuters MarketScan ${ }^{\circledR}$ Commercial Claims and Encounters Database (C) 2010. Patients were aged 18 to 64 receiving and not receiving BMP with a primary (C2-C7) cervical spine fusion. All outcomes were defined by ICD-9 and CPT codes. Complications were analyzed as any complication and stratified by nervous system,

\footnotetext{
(C) 2013 Elsevier Inc. All rights reserved.

Corresponding Author: Adam P. Goode, DPT, PhD, Assistant Professor, Department of Community and Family Medicine, Duke University School of Medicine, Adam.goode@ duke.edu, 919-681-6154.

Publisher's Disclaimer: This is a PDF file of an unedited manuscript that has been accepted for publication. As a service to our customers we are providing this early version of the manuscript. The manuscript will undergo copyediting, typesetting, and review of the resulting proof before it is published in its final citable form. Please note that during the production process errorsmaybe discovered which could affect the content, and all legal disclaimers that apply to the journal pertain.
} 
wound, and dysphagia or hoarseness. Cervical revision fusions were determined in the one-year follow-up. Hospital re-admission discharge records defined thirty-day hospital re-admission and reason for re-admission. The utilization of at least one healthcare service of cervical spine imaging, epidural usage or rehabilitation service was examined. Poisson regression models were used to estimate the relative risk (RR) and 95\% confidence intervals (CI). Linear regression was used to determine time to hospital re-admission. Results were stratified by anterior or posterior and circumferential approach.

Results-Patients receiving BMP were $29 \%$ more likely to have a complication (adjusted relative risk $[\mathrm{aRR}]=1.29((95 \% \mathrm{CI} 1.14$ to 1.46$))$ and nervous system complication $(\mathrm{aRR}=1.42$ ((95\% CI 1.10 to 1.83$))$. Cervical revision fusions were more likely among patients receiving BMP (aRR=1.69 ((95\% CI 1.35 to 2.13)). The risk of 30-day re-admission was greater with BMP use ( $\mathrm{aRR}=1.37$ ((95\% CI 1.07 to 1.73$)$ ), and re-admission occurred on average $27.4 \%$ sooner. Patients receiving BMP were more likely to receive computed tomography scans (aRR=1.34 $((95 \%$ CI 1.06 to 1.70$))$ and epidurals with anterior surgical approaches (aRR=1.29 ((95\% CI 1.00 to 1.65$))$.

Conclusions-These findings question both the safety and effectiveness of off-label BMP use in primary cervical spine fusions.

\section{Keywords}

Bone Morphogenetic Protein; Cervical Revision Fusion; Complications; Health Care Utilization

An estimated 1.3 million cervical procedures were performed in the US between 2002 and 2009 , with a significant increasing trend of procedures across these years. ${ }^{1}$ These procedures have been accompanied by a shorter length of hospital stays (LOS) and increasing number of procedures on patients with comorbidities. ${ }^{2}$ National estimates indicate that $3.9 \%$ of patients will have a complication following cervical spine fusion with this estimate becoming higher with increasing patient age and among posterior or circumferential approaches. ${ }^{3}$ Hospital re-admission related to cervical spine fusion complications are not uncommon $(7.9 \%)^{4}$ and re-operation rates have been estimated to be $2.5 \%$ per year following initial cervical spine surgery. ${ }^{5}$

Bone morphogenetic protein (BMP) is a novel technology designed to stimulate bone growth and increase the likelihood of bony fusion. ${ }^{6}$ This could be especially meaningful for patients who are at risk of nonunion following spine fusion. ${ }^{7}$ Approved by the Food and Drug Administration (FDA) in 2002, for limited use in the lumbar spine ${ }^{8}$, BMP use has been off-label in the cervical spine ${ }^{9}$, thoracic spine ${ }^{9}$ and during pediatric spinal arthrodesis ${ }^{10}$. In 2006, national estimates indicated that BMP was used in $25 \%$ of all spinal fusions with a high rate of complication occurrence. ${ }^{9}$ In addition, over the past few years the safety of BMP use has raised concerns with conflicting study results and questionable omission of related complications in prior publications. ${ }^{11}$

Nationwide estimates of complications related to BMP use with cervical spine fusion have been primarily perioperative; limiting the understanding of the effects that BMP exposure has following index hospital discharge. In the lumbar spine, within a one-year period, BMP

Spine J. Author manuscript; available in PMC 2015 September 01. 
use has been associated with a decrease in revision fusions procedures ${ }^{12}$ and complication rates related to BMP use have been much lower than those found in the cervical spine. ${ }^{9,13}$ We are unaware of any national level data specifically determining revision fusions in the cervical spine among those receiving BMP during a primary cervical spine fusion. 30-day hospital re-admissions have been reported to be significantly greater among Medicare beneficiaries receiving BMP during cervical spine fusion. ${ }^{4}$ Whether this is true in a younger population has not been investigated on a national level. To fill these gaps in the literature, we analyzed a large nationwide U.S claims database to examine patients aged 18-64 with one-year continuous insurance enrollment, receiving and not receiving BMP, during a primary cervical spine fusion to determine: 1) the one-year risk of complications and revision fusion surgery 2) differences in 30-day re-admission rates, and 3) differences in the utilization of rehabilitation services, imaging, or epidural pain management. We hypothesized that the use of BMP would increase rates of complications and subsequent revision fusion, result in higher hospital re-admission rates, and a greater proportion of healthcare services utilized over a one-year period.

\section{Methods}

Data for these analyses come from the Thompson Reuters MarketScan® Commercial Claims and Encounters Database (c) 2010 administered by Truven Health Analytics (formerly Thomson Reuters Inc., New York, NY). These data are deidentified U.S health insurance claims including both inpatient and outpatient settings. Over 100 different insurance companies nationwide and large employers contribute to the database, with some portions of the US, such as the South represented more than the Northeast. These include fee-for-service, preferred provider organizations, and capitated health plans. ${ }^{14}$ This database has been used to establish national estimates related to surgical outcomes ${ }^{15,16}$ as well as outcomes related to BMP use in the lumbar spine ${ }^{12}$. Data were collected from the database utilizing International Classification of Diseases, $9^{\text {th }}$ edition Clinical Modification (ICD-9) and/or Current Procedural and Terminology, $4^{\text {th }}$ edition (CPT).

Patients $>=18-64$ years of age and undergoing a primary cervical spine (C2-C7) fusion $(\mathrm{n}=94,364)$ were eligible. Cervical fusions were classified by anterior (ICD-9: 81.02 or CPT: 22554), posterior (ICD-9: 81.03 or CPT: 22600), or circumferential (both anterior and posterior approaches on the same date) from 2002 (the first year of FDA approved BMP use) to year 2009 (last available year which meets our inclusion criteria). Only patients with one-year of continuous health insurance enrollment from the date of fusion were eligible $(n=64,283)$. Patients with trauma, spine infection and spine cancer were excluded $(n=2,346)$. Atlas-axis (C1-C2) fusions were not included, as the ICD-9 coding does not distinguish between surgical approaches (i.e., anterior or posterior).

The primary exposure was BMP (ICD-9: 84.52). The proportion of BMP use and overall cervical spine fusions were examined by study year. Covariates at the time of index surgery included; Metropolitan Statistical Area (MSA) of the beneficiary (categorized as a urban/ unknown or rural region), age (continuous), gender, insurance type categorized as capitated (no dollar amount is set to cover costs) or non-capitated (a fixed dollar amount is set to cover costs) and unknown insurance type, number of levels fused (categorized as 2-3 
(ICD-9: 81.62 and CPT: 22845 and 22842) or 4+ levels (ICD-9: 81.63 and CPT: 22846 and 22843 ) and primary admission diagnosis (categorized similar to Cahill and colleagues ${ }^{9}$ as either disk herniation or degenerative disease [ICD-9: 722.0-722.8, 722.9, 724.0, 723.7, $721,738.4$ ] or other diagnoses). The Elixhauser Comorbidity Index ${ }^{17,18}$ was used to identify comorbidities from both inpatient and outpatient claims in the 3 months prior to and on date of the index surgery. Comorbidities were categorized by the number of comorbidities per patient as $0-3+$ (few patients had greater than 3 comorbidities). Hospital region was database defined as South, West, Northeast and North Central.

Complications were classified similar to Cahill et al. ${ }^{9}$ by ICD-9 coding. Any surgical or medical complication (996.0-999.0), medical complications included myocardial infarction, shock, deep vein thrombosis, pneumonia and pulmonary embolus (997.1, 410.0-410.9, 998.0, 997.3, 415.1, 997.2). Nervous system complications included stroke, hemorrhage and other nervous system complications (997.0-997.9). Wound related complications included infection, dehiscence, seroma and hematoma (998.1, 998.11, 998.12, 998.13, 998.3, 998.31, 998.32, 998.83, 998.5, 999.3, 998.51, 998.59). Complications related to dysphagia/ hoarseness (478.30, 478.31, 478.32, 478.33, 478.34, 784.4, 787.2). Multiple complications in the same classification were not included and categories of complication are not mutually exclusive. Cervical revision fusion surgeries in the one-year period following index surgery were identified by anterior and posterior approaches (82.32 and 82.33).

Thirty-day re-admissions were defined as a hospital admission within 30 days of index surgery discharge. Time, in days, was measured from the date of discharge to the date of readmission. Common reasons for re-admission were determined from primary ICD-9 diagnosis coding.

The utilization of rehabilitation services (physical therapy [CPT: 97001, 97002, 97110, 97140, 97124, 97150], speech therapy [CPT: 92610 and 92611] and occupational therapy [ICD-9: 93.83 and CPT: 97003 and 97004]), spine imaging (cervical spine magnetic resonance imaging [ICD-9: 88.93 and 88.97 and CPT: 72141 and 72156] cervical spine CT scans [ICD-9: 87.03 and CPT: 72125, 72127, 72126], cervical spine plain film radiographs [ICD-9: 87.21-87.29 and CPT: 72040, 72050 and 72052], cervical myelogram [ICD-9:

87.21 and CPT: 72240 and 72126]), and cervical/thoracic epidurals (CPT: 62310 and 62318) were identified from claims in the one-year following the index surgery date.

\section{Statistical Analysis}

Counts with proportions and medians with interquartile range were used to describe univariate distributions. Since some of our outcomes were not rare (i.e., >10\% incidence), Poisson regression was used to model the relative risk (RR) and $95 \%$ confidence intervals (CI) of complications, revision fusions, re-admissions and healthcare utilization, accompanied by a robust variance estimator. ${ }^{19}$ Pearson chi-square p-values indicated an excellent fit for all models with p-values $>0.99$. Days to re-admission were logarithmic transformed to account for the positive skew of data (i.e., most re-admissions were not immediate and data were not normally distributed) and modeled with linear regression. Transformed coefficients represent the geometric mean or average time to hospital readmission. Results were stratified by anterior surgical approach, however due to the 
relatively small sample, posterior and circumferential approaches were combined in separate strata. We explored whether there were differences between the risk of any complication or hospital re-admission before and after the peak use of BMP in our data with an interaction term between year of BMP use and study year dichotomized at <2006 vs. $>=2006$. Unknown values for the levels of fused vertebrae were imputed according to Rubin's rules ${ }^{20}$ with 50 imputations in each multivariable model. Diagnostics from imputation models indicated no gross differences between the observed and imputed values and reasonable completed distributions. All regression models were adjusted for age, gender, MSA of the beneficiary, imputed levels of fusion, insurance type, hospital region, admission diagnosis, comorbidities and study year. Chi square tests were used for differences in proportions. Alpha was set at $\mathrm{p}<0.05$, all analyses were un-weighted and performed in Stata 12.0 (Stata Corp, College Station, Tx).

We conducted several simple sensitivity analyses. We examined our results with and without imputed data for levels of cervical spine fusion (Appendix table 1) and found no appreciable differences in the strength of the estimates (i.e., <5\% change in estimates). We decided to maintain the imputation models for these analyses since the imputed estimates were more precise as there was as there was a large amount of missing data for this important variable (10\%) and this variable was strongly associated with BMP use. The propensity for BMP use was examined with matched models (Coarsened Exact Matching ${ }^{21}$ ). No appreciable differences ( $<10 \%$ change in estimate) were found between adjusted and matched models with our major outcomes nor were there changes in statistical significance. A majority of the estimates from unmatched models were more conservative or did not differ in strength of the estimate (i.e., calculated as a the change in the natural log of the estimates) when compared to the matched models with the exception of revision fusions (Appendix table 2). We report the adjusted models due to the loss of data that can occur from a lack of matching, especially with a rare exposure, which limited our ability to perform stratified analysis by surgical approach. Finally, we determined if there were differences in the distribution of BMP and covariates among those patients meeting and not meeting our enrollment eligibility (see Appendix tables 3 and 4). These findings indicate those meeting and not meeting the one-year eligibility requirements are similar in BMP distribution, demographic and clinical characteristics, however patients not meeting oneyear enrollment eligibility had a higher proportion of comorbidities.

\section{Results}

These analyses consist of 61,937 patients with one-year continuous insurance enrollment following a primary $(\mathrm{C} 2-\mathrm{C} 7)$ cervical spine fusion. The majority of fusions utilized an anterior approach $(92.8 \%, \mathrm{n}=57,484)$ with a smaller proportion of posterior $(5.2 \%, \mathrm{n}=3,209)$ and circumferential $(2.0 \%, \mathrm{n}=1,244)$ approaches. The use of BMP rose from $0.24 \%$ in the year 2002 to peak (4.8\%) in the year 2007 and declined to $2.0 \%$ in 2009. The proportion of overall primary cervical spine fusions increased to 11,561 cervical fusions performed in 2008 (18.7\% of the total sample). (Figure 1)

Table 1 describes both individual patient and hospital level characteristics by BMP status. The use of BMP was similar across age, gender, and beneficiary MSA. BMP use was 
strongly associated with posterior (relative risk $[\mathrm{RR}]=1.67$ ((95\% CI 1.41 to 1.98$)$ ) and circumferential approaches ( $R R=1.87$ ( $(95 \%$ CI 1.46 to 2.41$)$ ), and 4+ levels fused $(\mathrm{RR}=1.96$ ((1.76 to 2.18$))$. The use of BMP was strongly and independently related to the number of comorbidities, with increasing use of BMP with increasing comorbidities $(\mathrm{p}<0.001$ for differences in comorbidity categories).

Table 2 presents the events, unadjusted and adjusted RRs with 95\% CIs for complications in a one-year period by BMP status. Patients receiving BMP, with any approach, were $29 \%$ more likely to have any complication in a one-year period (adjusted relative risk $[\mathrm{aRR}]=1.29$ ((95\% CI 1.14 to 1.46)) that was similar for anterior approaches but stronger for posterior/ circumferential approaches. There was a strong risk of nervous system complication (aRR=1.42 ((95\% CI 1.10 to 1.83$)$ ) that was similar for anterior approaches and posterior/ circumferential approaches. A high risk for revision fusion surgery in a one-year period with BMP use (aRR=1.69 ((95\% CI 1.35 to 2.13)) and similar for anterior approaches and posterior/circumferential approaches.

The years when BMP was used significantly modified the risk of any complication. Prior to the year 2006, there was a high risk of any complication (aRR=1.60 ((95\% CI 1.30 to 1.97)), whereas in 2006 and after, this risk decreased ( $\mathrm{aRR}=1.21$ ((95\% CI 1.08 to 1.37)) but remained significant (ratio of aRR=1.32 ((95\% CI 1.04 to 1.67$)$ ).

Table 3 presents the risk of 30-day admission following index hospitalization discharge and days to that re-admission. Of the 61,383 fusions discharged (excluding death [n=5], rehabilitation admission [ $n=471]$ and $>30$ day LOS $[n=78]), 2.7 \%(n=1,643)$ had a 30-day hospital re-admission. Patients receiving BMP had a 34\% increased risk of 30-day readmission ( $\mathrm{aRR}=1.34$ ((95\% CI 1.06 to 1.70$))$ and a similar risk for anterior approaches $(\mathrm{aRR}=1.33$ ((95\% CI 1.01 to 1.75$))$. Common reasons for re-admission by patients receiving BMP versus not receiving BMP were: wounds ( $25.7 \%$ vs. $17.7 \%, \mathrm{p}=0.08)$, spondylosis or intervertebral disc related ( $18.9 \%$ vs. $19.0 \%, \mathrm{p}=0.99)$, medical complication $(13.0 \%$ vs. $10.0 \%, \mathrm{p}=0.35)$, and dysphagia or edema of the larynx (9.5\% vs. $3.3 \%, \mathrm{p}<0.01)$. Readmission on average was $27.4 \%$ sooner among patients receiving BMP $(-27.4 \%$ ( $(95 \%$ CI $-38.9 \%$ to $-13.6 \%))$. No significant interaction $(\mathrm{p}=0.36)$ between year and BMP use was found with 30-day re-admission.

Table 4 presents the utilization of rehabilitation services, imaging, and epidurals in the year following index surgery. Regardless of fusion approach, patients receiving BMP were 30\% more likely to have cervical spine CT scans (aRR=1.30 ((95\% CI 1.18 to 1.43)). These results were similar with anterior approaches. Epidural/block use was significantly higher $(\mathrm{aRR}=1.29((95 \% \mathrm{CI} 1.00$ to 1.65$))$ among patients receiving BMP with an anterior approach. Epidural use (12.5\% vs. $5.2 \%$, p $<0.001)$ and CT scans ( $40.3 \%$ vs. $24.3 \%$, $\mathrm{p}<0.001$ ) were more common among patients having a revision fusion if they received BMP during a primary cervical fusion. 


\section{Discussion}

The use of BMP during cervical spine fusions has received considerable attention over the past several years. This in part due to the high number and severity of complications with BMP use that has been alarming and warrants intense scrutiny. ${ }^{22}$ Adverse events attributed to BMP use were relatively rarely reported in the early experience. Early clinical trials determining the efficacy of BMP noted no adverse events in the cervical spine. ${ }^{23,24}$ However, clinical trials are not typically statistically powered to determine these differences. ${ }^{25}$ Moreover, some have indicated that adverse events related to BMP may be underestimated ${ }^{11}$ and possibly not known ${ }^{26}$. Although certainly not without limitation, this makes observational studies incredibly important for understanding rare outcomes such as this. Across most all of our complication outcomes there was a noticeable increased risk of complication associated with the use of BMP. This was especially true of the one-year risk of any complication following a primary cervical spine fusion despite the surgical approach utilized. The ICD9 codes utilized for these complications represent a broad range of medical and surgical complications and provide a larger scale view of complications related to BMP use, some of which may be more likely to occur following index hospitalization that may have not been captured in previous perioperative studies.

Our analyses revealed that patients receiving BMP were at increased risk of nervous system complications. This contrasts a previous study, which reported no delayed neurological deficits, associated with BMP use, however these findings are reported for BMP use among lumbar, thoracic and cervical fusions combined. ${ }^{27}$ Reasons related to neurological complication found in our study might be related to ectopic bone in the spinal canal, reported by Wong et al. ${ }^{28}$, which may contribute to neurologic compromise. A similar risk was found with posterior/circumferential approaches although the substantially smaller sample size in this subgroup is the likely reason for the decreased statistical power and imprecision found for this estimate. This may also be the case with medical complications. The strength of our estimates indicated a high risk of medical complication whereas the rare number of occurrences resulted in limited statistical power, which should be taken into consideration when determining benefit versus safety.

Our results regarding dysphagia/hoarseness contrast several previous studies and reviews. ${ }^{9,22,27,29,30}$ Differences in patient characteristics may be one explanation for this finding. Williams and colleagues ${ }^{27}$ report a significant risk of wound infections associated with anterior cervical approaches. However, their analyses were not adjusted for many of the covariates we which we found to be strong confounders (i.e., insurance, levels of fusion and comorbidities). Cahill and colleagues ${ }^{9}$ also reported increased associated wound infection with BMP use in data from the National Inpatient Sample. Patient age and related comorbidities may be one reason for the differences between our study results, as our sample was substantially younger due to the absence of Medicare claims. According to traditional statistical criteria our results for dysphagia/hoarseness among anterior cervical fusions are not significant, however this borderline significance should be considered when making judgments based upon patient safety. 
We found a 32\% greater risk of any complication with BMP use prior to the year 2006 . Some have reported that complications with BMP use have been intimately related to the dosage of BMP. ${ }^{22,31}$ This may be one reason for this significant decrease in the risk of complication observed in these analyses as these reports occurred near the year examined for this interaction effect. Despite the decline in risk after 2006, patients receiving BMP continued to have a significant risk of any complication. With claims data we are unable to determine the dosage and location of BMP used during these years and surgeon level practices that could greatly influence these estimates.

We determined the risk of cervical revision fusion surgery following BMP use within a oneyear period; a period of time with which the therapeutic effects of BMP use would be expected. Our work regarding revision contrasts several previous studies finding a high fusion rate in the cervical spine $23,32-36$ whereas others have found excessive bone growth, cyst formation and osteolysis ${ }^{37}$. The differences in sample size and methodologies between our study and these others make comparisons difficult. Our results regarding revision fusion should be interpreted with caution since we are unable to accurately determine if the revision fusion was of the primary cervical fusion in that same year. However, surgeons are typically less likely to conduct a revision fusion in the same year without necessity. Moreover, within our data (results not shown) a majority of those patients receiving BMP and requiring a revision fusion surgery also had a complication during that year. This link between complication, BMP use and revision surgery or other invasive intervention has also been found in reports to the FDA. ${ }^{26}$

General interest in hospital re-admission has increased in recent years. ${ }^{38}$ Similar to a recent study by Wang and colleagues ${ }^{4}$, Medicare patients receiving BMP had an increased risk of hospital re-admission. Several reasons for re-admission were identified in these analyses and could be considered modifiable complications. Dysphagia and larynx edema is one such complication that has been linked to BMP use and is considered a serious adverse event needing emergency medical intervention. ${ }^{39}$ Previous studies examining re-admission complications related to dysphagia and larynx edema have been case reports or small samples with limited generalizability. ${ }^{29,40}$ Our findings indicate this is a significant reason for 30-day re-admission related to BMP use. The median time to re-admission in our study also coincides with times when a serious adverse event such as this is likely to occur (i.e., 714 days). ${ }^{39}$

We found a greater utilization of imaging and epidural pain management among patients receiving BMP. Patients receiving BMP during primary fusion had increased use of CT scans with either anterior or posterior/circumferential and epidural use among anterior approaches. The increased use of CT scans and epidural use may be related to complications influencing bony union and continued symptoms among these patients, as a higher proportion of these patients had a revision fusion in the one-year period.

Our study is not without limitations. These results may not be generalizable to an older population, as Medicare claims were not included. However, the known differences between complications, comorbidities and re-admissions may preclude pooling age groups into a single estimate. The absence of Medicare claims data, is likely a large reason why our 
estimates of cervical procedures, BMP use and complication rates are lower than previous published nationwide estimates. We also had a substantial number (34\%) of patients who were not eligible due to our enrollment criteria. Our sensitivity analysis did not reveal any substantial reasons between those included and not included with the exception of comorbidities. With claims data there is the possibility of miscoding, resulting in misclassification of the exposure or outcomes. We do not feel that there are any specific reasons why this would be differential by BMP status. These analyses are of observational data and not experimental. We adjusted for confounding factors that have been found in previous studies. The majority of difference in unadjusted and adjusted estimates was due to the presence of comorbidities and levels of fusion. For our major outcomes, the effect was consistently and significantly greater than the null (i.e., RR above 1.0). While residual confounding is certainly possible, it is unlikely that this would result in a statistically significant or clinically important effect from the administration of BMP since our sensitivity analysis indicated that most of the matched models, which theoretically would adjust for confounding by indication, were not significantly different from unmatched models. Lastly, despite our large sample size we were unable to stratify our regression models with some important findings (e.g., nervous system complications) by ICD-9 diagnostic codes to better understand the clinical implications of this particular diagnosis and BMP use.

We find consistent evidence of complications with BMP use in primary cervical spine fusion within a one-year period, a period of time that has not been examined in previous reports. In contrast to the lumbar spine, BMP use during cervical spine fusion was not associated with a decrease in revision fusion surgery procedures. The use of BMP during primary cervical spine surgery resulted in a higher hospital re-admission rate and increased healthcare utilization. Results from these analyses question both the safety and effectiveness in the offlabel use of BMP for primary cervical spine fusions. Our findings, however, represent the past several years and recent evidence has improved our understanding of the safety of BMP use. In our data, the use of BMP during primary cervical spine fusions appears to be declining. This may be due to the recognized complications associated with BMP use, as complications are so prevalent with anterior cervical spine procedures that many surgeons no longer use BMP in this area. ${ }^{41}$ Efforts to create a guideline driven approach to the utilization of BMP are ongoing ${ }^{25}$ and greatly needed in order to better inform clinicians and prevent undue harm to patients.

\section{Supplementary Material}

Refer to Web version on PubMed Central for supplementary material.

\section{Acknowledgments}

Funding source: This project is considered to be part of the primary authors (Dr. Adam Goode, DPT, PhD) Kaward through Agency for Health Care Research and Quality K-12 Comparative Effectiveness Career Development Award (HS19479-01). Funding for APG is also received from the NIH Loan Repayment Program, National Institute of Arthritis Musculoskeletal and Skin Diseases (1-L30-AR057661-02). 


\section{References}

1. Oglesby M, Fineberg SJ, Patel AA, Pelton MA, Singh K. Epidemiological trends in cervical spine surgery for degenerative diseases between 2002 and 2009. Spine. 2013; 38(14):1226-1232. [PubMed: 23403550]

2. Goode AP, Carey TS, Jordan JM. Low back pain and lumbar spine osteoarthritis: how are they related? Curr Rheumatol Rep. 2013; 15(2):305. [PubMed: 23307577]

3. Wang MC, Chan L, Maiman DJ, Kreuter W, Deyo RA. Complications and mortality associated with cervical spine surgery for degenerative disease in the United States. Spine. 2007; 32(3):342-347. [PubMed: 17268266]

4. Wang MC, Shivakoti M, Sparapani RA, Guo C, Laud PW, Nattinger AB. Thirty-day readmissions after elective spine surgery for degenerative conditions among US Medicare beneficiaries. Spine J. 2012; 12(10):902-911. [PubMed: 23098615]

5. King JT Jr, Abbed KM, Gould GC, Benzel EC, Ghogawala Z. Cervical spine reoperation rates and hospital resource utilization after initial surgery for degenerative cervical spine disease in 12,338 patients in Washington State. Neurosurgery. 2009; 65(6):1011-1022. discussion 1022-1013. [PubMed: 19934960]

6. Hsu WK, Wang JC. The use of bone morphogenetic protein in spine fusion. Spine J. 2008; 8(3): 419-425. [PubMed: 18375186]

7. Burkus JK, Sandhu HS, Gornet MF, Longley MC. Use of rhBMP-2 in combination with structural cortical allografts: clinical and radiographic outcomes in anterior lumbar spinal surgery. The Journal of bone and joint surgery. 2005; 87(6):1205-1212. American volume. [PubMed: 15930528]

8. Administration. USFaD. [Accessed 11/27, 2012.] InFUSE Bone Graft/LT-CAGE Lumbar Tapered Fusion Device- P000058. Available at: http://www.fda.gov/MedicalDevices/ ProductsandMedicalProcedures/DeviceApprovalsandClearances/Recently-ApprovedDevices/ ucm083423.htm

9. Cahill KS, Chi JH, Day A, Claus EB. Prevalence, complications, and hospital charges associated with use of bone-morphogenetic proteins in spinal fusion procedures. Jama. 2009; 302(1):58-66. [PubMed: 19567440]

10. Dodwell E, Snyder B, Wright J. Off-label use of bone morphogenetic proteins in pediatric spinal arthrodesis. Jama. 2012; 308(14):1429-1432. [PubMed: 23047351]

11. Carragee EJ, Hurwitz EL, Weiner BK. A critical review of recombinant human bone morphogenetic protein-2 trials in spinal surgery: emerging safety concerns and lessons learned. Spine J. 2011; 11(6):471-491. [PubMed: 21729796]

12. Cahill KS, Chi JH, Groff MW, McGuire K, Afendulis CC, Claus EB. Outcomes for single-level lumbar fusion: the role of bone morphogenetic protein. Spine. 2011; 36(26):2354-2362. [PubMed: 21311404]

13. Deyo RA, Ching A, Matsen L, Martin BI, Kreuter W, Jarvik JG, et al. Use of bone morphogenetic proteins in spinal fusion surgery for older adults with lumbar stenosis: trends, complications, repeat surgery, and charges. Spine. 2012; 37(3):222-230. [PubMed: 21494195]

14. HealthcareT. Health Research Data for the Real World: The MarketScan Databases 2010. 2012. http://thomsonreuters.com/products_services/healthcare/healthcare_products/pharmaceuticals/ epidemiology_res/mktscan_res_db

15. MacKenzie EJ, Jones AS, Bosse MJ, Castillo RC, Pollak AN, Webb LX, et al. Health-care costs associated with amputation or reconstruction of a limb-threatening injury. The Journal of bone and joint surgery. 2007; 89(8):1685-1692. American volume. [PubMed: 17671005]

16. Krupski TL, Foley KA, Baser O, Long S, Macarios D, Litwin MS. Health care cost associated with prostate cancer, androgen deprivation therapy and bone complications. J Urol. 2007; 178(4 Pt 1): 1423-1428. [PubMed: 17706711]

17. Elixhauser A, Steiner C, Harris DR, Coffey RM. Comorbidity measures for use with administrative data. Med Care. 1998; 36(1):8-27. [PubMed: 9431328]

18. Quan H, Sundararajan V, Halfon P, Fong A, Burnand B, Luthi JC, et al. Coding algorithms for defining comorbidities in ICD-9-CM and ICD-10 administrative data. Med Care. 2005; 43(11): 1130-1139. [PubMed: 16224307] 
19. Zou G. A modified poisson regression approach to prospective studies with binary data. Am J Epidemiol. 2004; 159(7):702-706. [PubMed: 15033648]

20. Rubin, DB. Multiple Imputation for Nonresponse in Surveys. New York, NY: 1987.

21. Blackwell M, Iacus S, King G, Porro G. cem: Coarsened exact matching in Stata. Stata Journal. 2009; 9(4):524-546.

22. Shields LB, Raque GH, Glassman SD, Campbell M, Vitaz T, Harpring J, et al. Adverse effects associated with high-dose recombinant human bone morphogenetic protein-2 use in anterior cervical spine fusion. Spine. 2006; 31(5):542-547. [PubMed: 16508549]

23. Baskin DS, Ryan P, Sonntag V, Westmark R, Widmayer MA. A prospective, randomized, controlled cervical fusion study using recombinant human bone morphogenetic protein-2 with the CORNERSTONE-SR allograft ring and the ATLANTIS anterior cervical plate. Spine. 2003; 28(12):1219-1224. discussion 1225. [PubMed: 12811263]

24. Boakye M, Mummaneni PV, Garrett M, Rodts G, Haid R. Anterior cervical discectomy and fusion involving a polyetheretherketone spacer and bone morphogenetic protein. J Neurosurg Spine. 2005; 2(5):521-525. [PubMed: 15945426]

25. Carragee EJ, Baker RM, Benzel EC, Bigos SJ, Cheng I, Corbin TP, et al. A biologic without guidelines: the YODA project and the future of bone morphogenetic protein-2 research. Spine J. 2012; 12(10):877-880. [PubMed: 23199819]

26. Woo EJ. Recombinant human bone morphogenetic protein-2: adverse events reported to the Manufacturer and User Facility Device Experience database. Spine J. 2012; 12(10):894-899. [PubMed: 23098616]

27. Williams BJ, Smith JS, Fu KM, Hamilton DK, Polly DW Jr, Ames CP, et al. Does BMP increase the incidence of perioperative complications in spinal fusion? A comparison of 55,862 cases of spinal fusion with and without BMP. Spine. 2011

28. Wong DA, Kumar A, Jatana S, Ghiselli G, Wong K. Neurologic impairment from ectopic bone in the lumbar canal: a potential complication of off-label PLIF/TLIF use of bone morphogenetic protein-2 (BMP-2). Spine J. 2008; 8(6):1011-1018. [PubMed: 18037352]

29. Smucker JD, Rhee JM, Singh K, Yoon ST, Heller JG. Increased swelling complications associated with off-label usage of rhBMP-2 in the anterior cervical spine. Spine. 2006; 31(24):2813-2819. [PubMed: 17108835]

30. Vaidya R, Carp J, Sethi A, Bartol S, Craig J, Les CM. Complications of anterior cervical discectomy and fusion using recombinant human bone morphogenetic protein-2. European spine journal. 2007; 16(8):1257-1265. [PubMed: 17387522]

31. Dickerman RD, Reynolds AS, Morgan BC, Tompkins J, Cattorini J, Bennett M. rh-BMP-2 can be used safely in the cervical spine: dose and containment are the keys! Spine J. 2007; 7(4):508-509. [PubMed: 17521966]

32. Lanman TH, Hopkins TJ. Early findings in a pilot study of anterior cervical interbody fusion in which recombinant human bone morphogenetic protein- 2 was used with poly(L-lactide-co-D, Llactide) bioabsorbable implants. Neurosurg Focus. 2004; 16(3):E6. [PubMed: 15198494]

33. Vaidya R, Carp J, Sethi A, Bartol S, Craig J, Les CM. Complications of anterior cervical discectomy and fusion using recombinant human bone morphogenetic protein-2. European spine journal : official publication of the European Spine Society, the European Spinal Deformity Society, and the European Section of the Cervical Spine Research Society. 2007; 16(8):12571265.

34. Vaidya R, Weir R, Sethi A, Meisterling S, Hakeos W, Wybo CD. Interbody fusion with allograft and rhBMP-2 leads to consistent fusion but early subsidence. The Journal of bone and joint surgery. 2007; 89(3):342-345. British volume. [PubMed: 17356146]

35. Aryan HE, Lu DC, Acosta FL Jr, Ames CP. Corpectomy followed by the placement of instrumentation with titanium cages and recombinant human bone morphogenetic protein-2 for vertebral osteomyelitis. J Neurosurg Spine. 2007; 6(1):23-30. [PubMed: 17233287]

36. Tumialan LM, Pan J, Rodts GE, Mummaneni PV. The safety and efficacy of anterior cervical discectomy and fusion with polyetheretherketone spacer and recombinant human bone morphogenetic protein-2: a review of 200 patients. J Neurosurg Spine. 2008; 8(6):529-535. [PubMed: 18518673] 
37. Klimo P Jr, Peelle MW. Use of polyetheretherketone spacer and recombinant human bone morphogenetic protein-2 in the cervical spine: a radiographic analysis. Spine J. 2009; 9(12):959966. [PubMed: 19574105]

38. Joynt KE, Jha AK. Thirty-day readmissions--truth and consequences. N Engl J Med. 2012; 366(15):1366-1369. [PubMed: 22455752]

39. Administration USFaD. FDA Public Health Notification: Life-threatening Complications Associated with Recombinant Human Bone Morphogenetic Protein in Cervical Spine Fusion. 2008. [Accessed 12/16, 2012.]

40. Perri B, Cooper M, Lauryssen C, Anand N. Adverse swelling associated with use of rh-BMP-2 in anterior cervical discectomy and fusion: a case study. Spine J. 2007; 7(2):235-239. [PubMed: 17321975]

41. Epstein NE. Pros, cons, and costs of INFUSE in spinal surgery. Surg Neurol Int. 2011; 2:10. [PubMed: 21297932] 


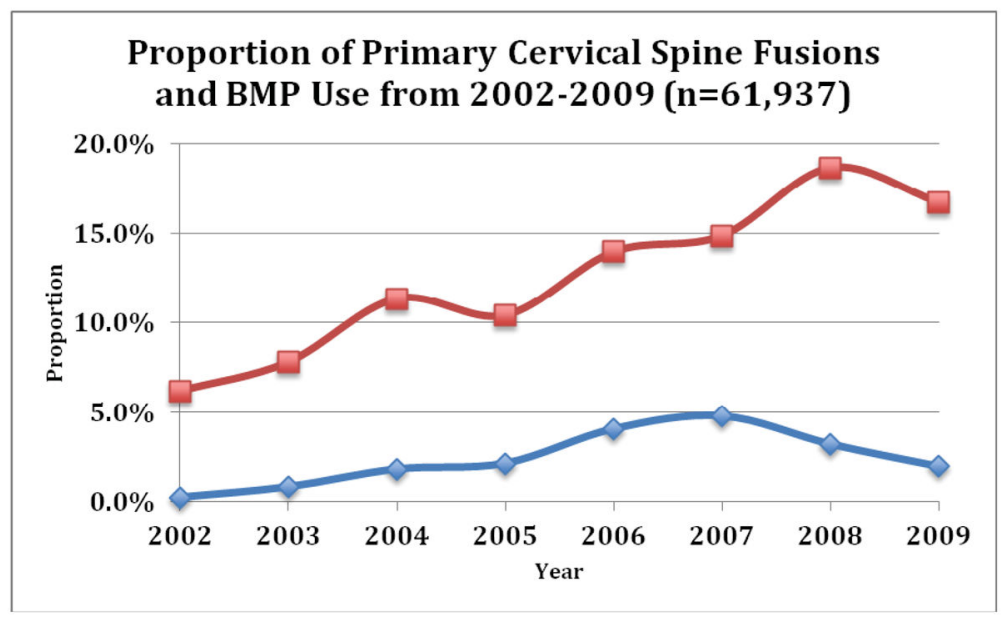

Figure.

Proportion of primary cervical spine fusions and use of BMP from 2002-2009 (n=61,937). Diamonds represent the proportion of BMP use and squares represent the overall proportion of cervical spine fusions. 
Table 1

Characteristics of patients and hospitals receiving or not receiving bone morphogenetic protein (BMP) during primary cervical spine fusion from 2002-2009

\begin{tabular}{|c|c|c|c|}
\hline Characteristic & No $B M P(n=60,260)$ & $\operatorname{BMP}(n=1,677)$ & BMP use relative risk $(95 \% \mathrm{CI})$ \\
\hline Age, mean (SD) & $49.7(8.1)$ & $50.0(8.1)$ & $1.00(1.00$ to 1.01$)$ \\
\hline \multicolumn{4}{|l|}{ Sex, n(\%) } \\
\hline Men & $27,339(45.4)$ & $731(43.6)$ & ref \\
\hline Women & $32,921(54.6)$ & $946(56.4)$ & $0.93(0.85$ to 1.03$)$ \\
\hline \multicolumn{4}{|l|}{ Insurance Type, n (\%) } \\
\hline Capitated or Unknown & $10,390(17.2)$ & $245(14.6)$ & ref \\
\hline Non-Capitated & $49,870(82.8)$ & $1,432(85.4)$ & $1.21(1.06$ to 1.39$)$ \\
\hline \multicolumn{4}{|l|}{ MSA, n (\%) } \\
\hline MSA & $47,467(78.8)$ & $1,306(77.9)$ & ref \\
\hline Non-MSA or Unknown & $12,793(21.3)$ & $371(22.1)$ & $1.03(0.93$ to 1.15$)$ \\
\hline \multicolumn{4}{|l|}{ Fusion Approach, n (\%) } \\
\hline Anterior & $56,005(92.9)$ & $1,479(88.2)$ & ref \\
\hline Posterior & $3,071(5.1)$ & $138(8.2)$ & 1.67 (1.41 to 1.98$)$ \\
\hline Circumferential & $1,184(2.0)$ & $60(3.6)$ & $1.87(1.46$ to 2.41$)$ \\
\hline \multicolumn{4}{|l|}{ Vertebral Levels Fused, n (\%) } \\
\hline $2-3$ & $46,690(77.5)$ & $1,257(75.0)$ & ref \\
\hline$>=4$ & $7,483(12.4)$ & $405(24.2)$ & $1.96(1.76$ to 2.18$)$ \\
\hline Unknown & $6,087(10.1)$ & $15(0.9)$ & N/A \\
\hline \multicolumn{4}{|l|}{ Number of Comorbidities ${ }^{*}, \mathrm{n}(\%)$} \\
\hline 0 & $33,316(55.3)$ & $687(41.0)$ & ref \\
\hline 1 & $18,073(30.0)$ & $530(31.6)$ & $1.41(1.26$ to 1.58$)$ \\
\hline 2 & $6,228(10.3)$ & $295(17.6)$ & $2.24(1.96$ to 2.56$)$ \\
\hline $3+$ & $2,643(4.4)$ & $165(9.8)$ & 2.91 (2.47 to 3.43$)$ \\
\hline \multicolumn{4}{|l|}{ Diagnosis, n (\%) } \\
\hline disk herniation or degenerative disease & $45,655(75.8)$ & $1,229(73.3)$ & ref \\
\hline Other conditions & $14,605(24.2)$ & $448(26.7)$ & $1.14(1.02$ to 1.26$)$ \\
\hline \multicolumn{4}{|l|}{ Hospital Region, $\mathrm{n}(\%)$} \\
\hline South & $32,730(54.3)$ & $871(51.9)$ & ref \\
\hline North Central & $14,962(24.8)$ & $405(24.2)$ & $1.02(0.91$ to 1.14$)$ \\
\hline West & $8,538(14.2)$ & $373(22.2)$ & 1.61 (1.43 to 1.82$)$ \\
\hline Northeast or Unknown & $4,030(6.7)$ & $28(1.7)$ & $0.26(0.18$ to 0.39$)$ \\
\hline
\end{tabular}

MSA=metropolitan statistical area of beneficiary, ref=referent category,

* Comorbidities from the Elixhauser Comorbidity Index.

BMP use estimated with Poisson regression 


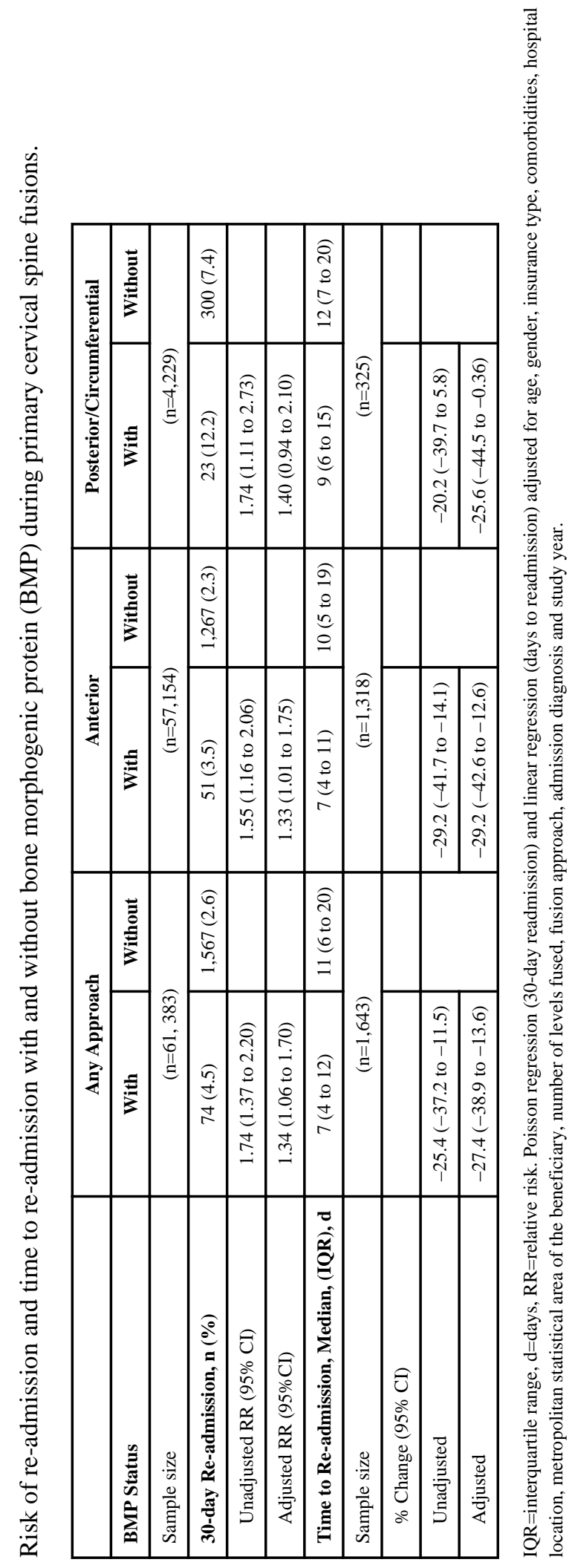

Spine J. Author manuscript; available in PMC 2015 September 01. 

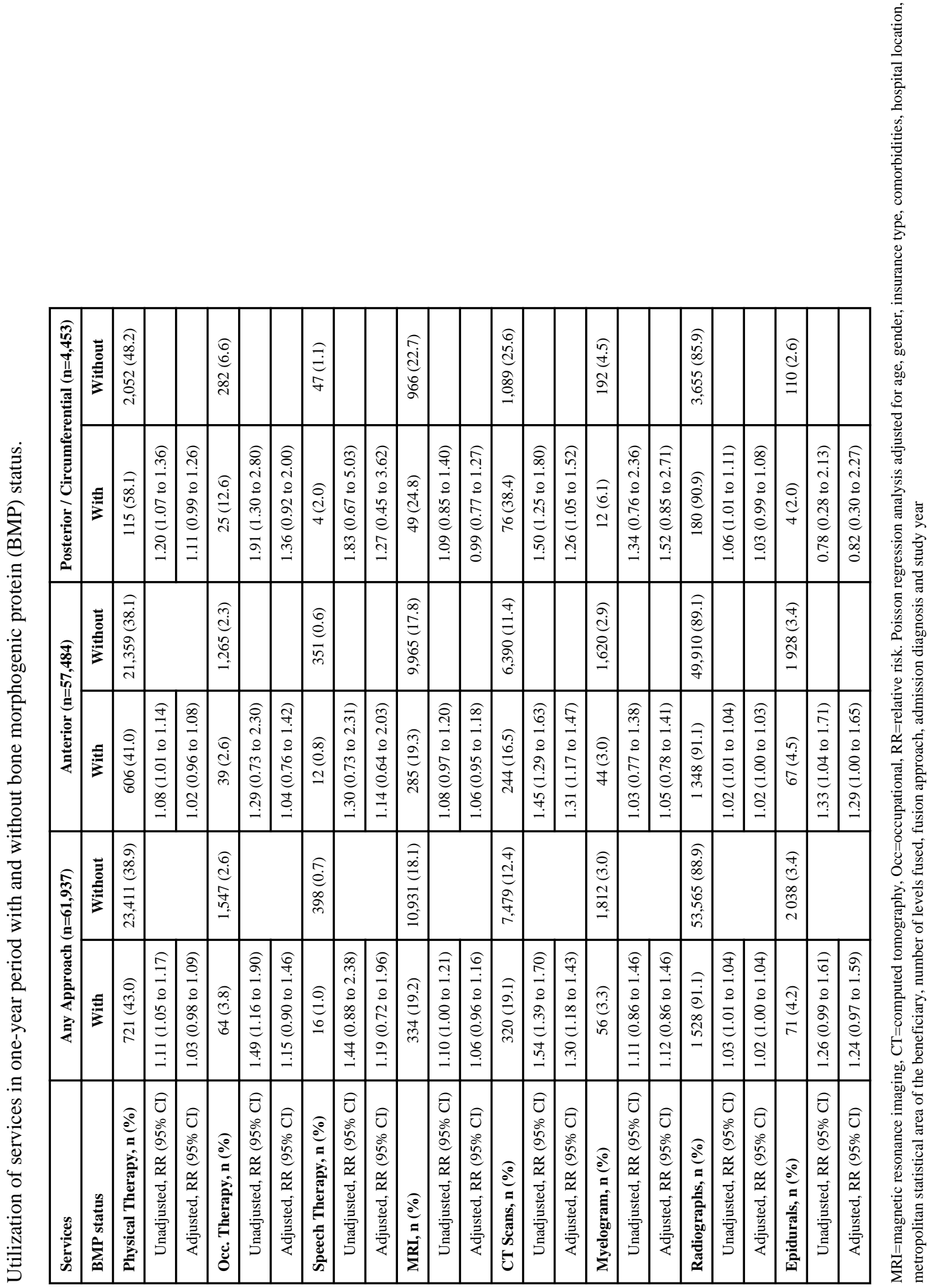